\title{
Promoting the Quality of Educational Institutions by Enhancing Educational Leadership
}

\author{
Samuel Gento \\ National University of Distance Education, Madrid, Spain \\ Günter L. Huber \\ University of Tübingen, Tübingen, Germany \\ Raúl González \\ National University of Distance Education, Madrid, Spain \\ Ascensión Palomares \\ University of Castilla-La Mancha, Albacete, Spain \\ Vicente J. Orden \\ National University of Distance Education, Madrid, Spain
}

\begin{abstract}
The initial aim of this research on the quality of educational institutions and educational leadership is to obtain valuable information (based on theoretical background and empirical data) regarding: (a) the importance or relevance given by professionals and key stakeholders to the different components, dimensions, and descriptors that define both the quality of educational institutions and educational leadership as practiced in such institutions; and (b) evidence revealing the presence of these components and demonstrating that the exercise of the leadership is being carried out in accordance with the descriptors of each dimension. The end aim of the study is by the information obtained to provide a basis for proposing strategies and alternatives to facilitate the improvement of educational institutions. Quality of education and quality of educational leadership are both matters of concern for education professionals, social and political leaders, and people in general. Education is considered today the main motor for the development of people and societies, and leadership in education is emerging as a fundamental factor for this improving change. This research is based on two fundamental pillars: (a) the analysis of the evidence and proposals of a number of relevant authors regarding the quality of education and educational leadership; and (b) the information provided by the key stakeholders. To obtain this information, we have been helped by professionals working in the education filed, by university students (of different courses in a number of academic institutions), and by colleagues who are members of the European Association on "Educational Leadership and Quality of Education". To collect empirical data, two questionnaires, one on the quality of educational institutions and the other on educational leadership in these institutions, have been designed. Both of them have been submitted to validation in order to check their appropriateness for measuring the included contents. Although the empirical data (in particular those collected from the questionnaires) are still provisional, they provide an indication of what the
\end{abstract}

Samuel Gento, Ph.D., full professor, Faculty of Education, National University of Distance Education.

Günter L. Huber, Ph.D., full professor, Institute of Educational Research, University of Tübingen.

Raúl González, Ph.D., associate professor, Faculty of Education, National University of Distance Education.

Ascensión Palomares, Ph.D., professor, Faculty of Education, University of Castilla-La Mancha.

Vicente J. Orden, M.A., collaborator professor, Faculty of Education, National University of Distance Education. 
profile of education in today's societies should be and how leadership could be exercised within educational institutions or entities. Data collected from 32 interviews have also been analysed. These data offer information about the most relevant features characterising an authentic educational or pedagogical profile of educational entities and of pedagogical or educational leadership.

Keywords: importance of quality, paradigm of total or integral quality, evidence of quality, identifiers of quality, predictors of quality, values as educational product, educational or pedagogical leadership dimensions, resources, processes, and results of quality

\section{Introduction}

\section{Research Purpose}

The purpose of this research is to study the relevant components and indicators of quality for educational institutions and the dimensions of educational leadership. The aim in analysing these topics is to obtain information with a view to improving the quality of educational institutions by fostering true educational leadership. The report on "improving school leadership", drawn up for the Organization for Economic Cooperation and Development (OECD) by Pont, Nusche, and Moorman (2008), declared that the quality of leadership in educational institutions plays a fundamental role in the improvement of educational practice and has therefore become a priority in the educational politics of the OECD and in the countries belonging to this organization.

Accordingly, the research set out to obtain information regarding the following objectives:

(a) To collect information on the importance that the most representative stakeholders in education and in educational institutions give to the components and elements that reveal the quality of educational institutions;

(b) To collect data regarding the degree, existence, reality, or effectiveness of these components and elements in educational institutions;

(c) To obtain information on the importance that the stakeholders attribute to the dimensions and features that show the implementation of pedagogical or educational leadership in educational institutions;

(d) To collect data regarding the degree, existence, reality, or effectiveness of the exercise of educational leadership in educational institutions;

(e) To relate the importance and evidence of the quality of educational institutions with the importance and evidence of the pedagogical or educational leadership in such institutions.

\section{Theoretical Background}

The theoretical background is taken from the literature on the quality of education, the quality of educational institutions, and the leadership exercised in educational institutions. Particular attention is given to reports on the quality of education in general and in relation to European countries. Studies on educational leadership are also taken into consideration for defining the theoretical framework.

If the quality of education is today a need widely felt by people and societies for their own development and progress, there is not a single educational system that could be considered as of true quality, tailored to the needs of individuals and the corresponding society; if it would not have the necessary resources, the processes and results appropriate to the quality paradigm and, even better, to the paradigm of total or integral quality.

Today's movement pro the quality of education has a number of precedents. Among the most notable are: 
(a) The contribution from the movement of effective schools (Scheerens, 1992);

(b) The movement pro improvement of educational institutions promoted by Hopkins and Lagerweig (1997);

(c) The movement pro school re-structuring driven by Stoll and Fink (1996).

Among the basic concerns of a good number of today's developed countries are the following:

1. Education is considered to be a vital factor determining the progress and competitiveness of a country;

2. There is a concern that investment made in educational systems does not appear to be as effective and profitable as might be expected.

The Programme for International Student Assessment (PISA) report of 2011 (OECD, 2012) on results obtained in reading, mathematics, and sciences, collected data of the evaluation of more than 500,000 students of 15 years old in 65 countries. At the top of the results table in mathematics are a number of countries from East Asia headed by Shanghai (with the highest number of 613 points, 119 higher than the OECD average of 494), followed by Singapore (with 573), Hong Kong (with 561), South Korea (with 554), Macao (with 538), and Japan (with 536). These countries, together with Liechtenstein, Switzerland, and the Low Countries, form the group of the 10 countries with the best results in mathematics.

Among the factors that seem to determine the good results in this evaluation, this PISA report emphasizes the following:

(a) Quality of teacher training;

(b) Teachers' acknowledgement and prestige;

(c) Autonomy of educational institutions (to design the curriculum and to carry out evaluations);

(d) Support given to students needing special care (due to their particular difficulties of different types);

(e) Students' effort to achieve ambitious objectives;

(f) Collaboration among teachers, parents, school principals, and authorities.

The effort made by the students and the acknowledgement that society gives to education appear to be particularly relevant. These factors would appear to have a greater influence on good results than the original socio-economic status of students, regions, and countries.

\section{Quality}

\section{Concept of Quality}

Although there are different interpretations of the concept of "quality" in general (Hopkins \& Lagerweig, 1997; Müller-Using, 2010; Murgatroid \& Morgan, 2002; Scheerens, 1992; Stoll \& Fink, 1996), we understand that "quality", with the meaning of integrality or totality, is "the trait attributable to individuals and collective entities whose structural and functional components meet the criteria of maximum suitability expected from them and that produce contributions or results valuable in the highest degree and accommodated to their own nature" (Gento, 2002, p. 11). In its complete and paramount meaning, quality could be considered as "the whole individual, authentic, integral, and supreme development of all the potentialities of a particular being or entity".

\section{Quality of Education}

The difficulty of defining the quality of education can be easily deduced if we consider that there are a number of definitions in education literature (Gerecht, 2010; Orden, 1989; Pérez \& Martínez, 1989). According to collected opinions, it must be considered that: 
1. Education is a complex reality;

2. There are important differences among conceptualizations on education;

3. The intellectual activity is not evident in itself, but can be seen by its results;

4. The student or person being educated is a free individual who determines his/her own behaviour in accordance with his/her own decision.

The fundamental purpose of education could help us define the result of an education of quality in the following way:

Education is the conscious promotion, implemented in an interrelated and participatory way, of the valuable condition of the whole dimensions of a person, who must tend to his/her own satisfaction and to the satisfaction of those with whom he/she lives in a given context and environment that must be protected and, when it is possible, improved. (Gento, 2002, p. 67)

This integral conception of education is far from the restrictive conceptions that consider education to be simply the acquisition of knowledge, or in a broadest sense, the promotion of learning. On the contrary, a human being not only possesses the ability to learn, nor even only the ability to develop his/her intellectual dimension; a human being also possesses other dimensions that must be considered as potentialities to be developed by an integral education of quality.

\section{Quality of Educational Institutions}

To synthesize different conceptions (Hodson \& Thomas, 2003; Lomas, 2007; Smith \& MacGregor, 2009; Wrigley, 2006), we offer our own definition of an educational institution of quality as "The one where the available resources, the processes carried out, and the results achieved are in keeping with the ideal theoretical model of a perfectly run educational institution" (Gento, 2002, p. 55). Of course, the specific model of what constitutes a perfectly run institution should be defined by each individual institution, although other external models could be used as a valid reference.

Wrigley (2006) defined the peculiarity of an educational institution that tries to improve its quality in the following way:

Before you set about improving schools, you need to work out what would count as good school. That depends on your view of society, your aspirations for your own people and your hope for the future. How we change schools depends on how we want to change the world. (p. 34)

Stressing the need to give the educational institutions their own autonomy, Sergiovanni (2004) stated that "When only uniform standards are imposed... these could undermine the local diversity, jeopardize the institutions' organization peculiarity, compromise its ability to answer the needed local expectancies and cripple its efforts to offer effective teaching and learning" (p. 83). As a conclusion to this reflection, Sergiovanni (2004) declared that "It should be left to teachers and students to define their own standards" (p. 92). Other authors (Smith \& MacGregor, 2009) considered that the external control of educational institutions is perceived by their members as intrusive and threatening to the institutions' autonomy without acting as promoter of change.

Assuming that each individual educational institution must define its own model of quality, the referential model we propose (Gento, 2002) to be submitted to the consideration of any educational community considers that within the quality of an educational institution, there are a number of components which are "identifiers" and others which are "predictors" (see Figure 1). The components of the first group act as evidence of quality, 
and the second group could be used to predict the possibility of quality. In fact, this is a purely methodological distinction to help us understand a global holistic system (a whole educational institution) and the way it operates.

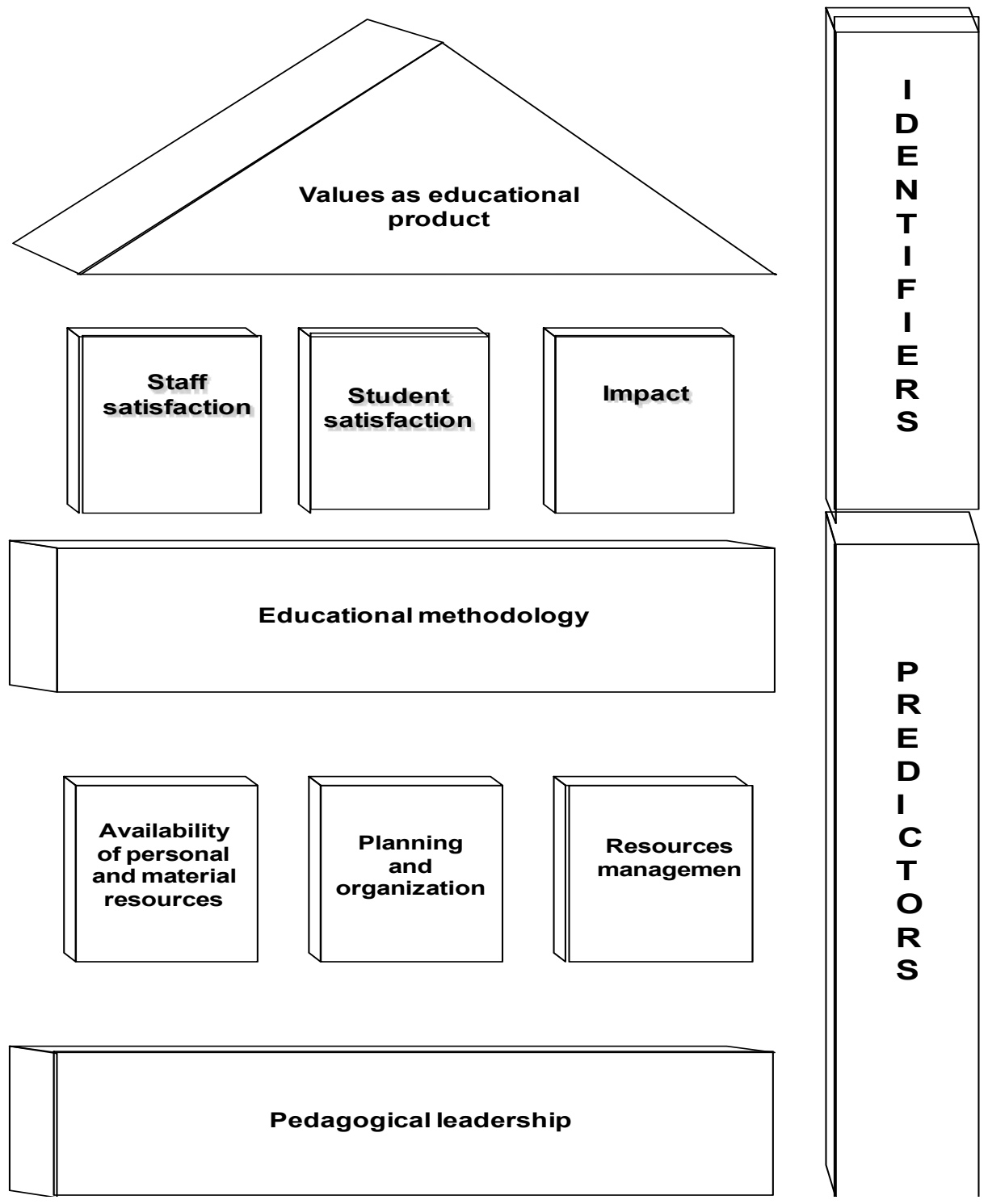

Figure 1. Model of quality of an educational institution (Gento, 2002).

\section{Identifiers of Quality of Educational Institutions}

The following are proposed as identifiers of the quality of an educational institution: (a) values as an educational product; (b) staff satisfaction; (c) student satisfaction; and (d) impact of education.

The educational product. In an educational institution, this product will obviously refer to the attainment of education. But this general concept implies some "elements that should be specified and made operative, in order to facilitate their control and assessment" (Burbules, 2004, p. 8). A conceptual analysis and reflection from comparative studies (United Nations Educational, Scientific, and Cultural Organization (UNESCO), 1972; Marín, 1993) shows that an integral conception of education, particularly within the European context, implies that the most specific asset of education are values that can be grouped in the following way: 

(a) Physical and emotional;
(b) Intellectual;
(c) Moral or ethical;
(d) Aesthetic or artistic;
(e) Socio-relational and environmental;
(f) Practical and utilitarian;
(g) Transcendental.

Student satisfaction. This quality indicator is similar to what in a producing company or agency of services is considered as "external customer satisfaction". It refers to the satisfaction of those whom the educational product is offered to or who obtain this product (although in an educational institution, students are besides co-agents of the educational product). For the analysis of student satisfaction, attention should be given to the following areas:

(a) Basic needs;

(b) Feeling of security;

(c) Acceptance within the group;

(d) Esteem received by the group members;

(e) Opportunity to freely develop themselves;

(f) Opportunity to participate.

Staff satisfaction. Staff satisfaction is related to organizational trends claiming staff participation as an essential principle (Gento, 1994). The whole assessment of staff satisfaction in a school affects all sectors that make up the institution, although the relative importance of the different sectors' satisfaction when considering its repercussion on the quality of the institution may be taken into account (Braslavski, 2004; Ministry of Education and Science, 1994). The following are possible elements leading to staff satisfaction:

(a) Attention to the material or physical conditions necessary to members' well-being and to the exercise of their duties;

(b) Job and professional security;

(c) Organization and function of the institution they work for;

(d) Obtained results (in this case, mainly student performance);

(e) Professional prestige.

Impact of education. This refers to the repercussion that the education received by people who have been students has on contexts where they live or carry out activities of different types. It is obvious that educational institutions of quality must offer educational products that not only improve life conditions and personal success of people who have been educated in them, but also that these educational products must have an improving effect on contexts where the subjects live and act. The main contexts where this impact could have influence are the following:

(a) The academic context: the impact that education has on the success of future educational or academic programmes (Gento, 2002, p. 101);

(b) The social and environmental context: impact on the society and on the surrounding environment they live in;

(c) The work and professional context: effect on the work and professional arena produced by people who, after finishing their studies in an educational institution, have entered the workplace; 
(d) The family context: effect produced on their families by people who have been students at the corresponding educational institution.

\section{Predictors of Quality of Educational Institutions}

The following are proposed predictors of quality for educational institutions: (a) educational methodology; (b) availability of personal and material resources; (c) planning and organization; (d) management of resources; and (e) educational leadership.

Educational methodology. Educational methodology refers to the specific way of carrying out the functions and tasks to attain educational objectives. According to its etymological origin and its conceptual content, this methodology is of meditational type, as it aims to offer the educational subject the possibility of objectives to be attained by educational processes. This methodology is primarily used in the classroom or space where students and teachers most frequently carry out their activity (Scheerens \& Creemers, 1989). The following may be considered to be the basic principles of an educational methodology of quality:

(a) Planned dedication: involving task dedication (individual and collaborative), planning and programming, organization, use of resources, assessment, and self-analysis;

(b) Adaptation: to people (pupils or students, teachers, parents, etc.), and to the environment and context (social, familiar, educational, and workplace);

(c) Empowerment of abilities: positive motivation, formative self-evaluation, positive expectancies, promotion of creativity, encouragement of problem solving, curriculum options, and extracurriculum options;

(d) Positive inter-relational atmosphere: emotional attention; sense of security, order, silence, or quietness; discipline; open and multidirectional communication; and positive interaction;

(e) Inter-relationship with other entities: with families; with social community; with productive, professional, and work sectors; with public administration; and with other institutions or entities.

Availability of personal and material resources. Within this component are included those personal and material elements that form the patrimony the educational institution possesses to perform its activity. Teachers are, undoubtedly, "a very important asset of an educational institution and highly relevant for its quality" (Ministry of Education and Science, 1994, pp. 81-97). But the institution also has other members, such as the non-teaching staff and all the other personnel (of vadministration, maintenance, cleaning, etc.). Students are also significant members of an educational institution and are a relevant factor for determining its quality. There are also material resources necessary for the smooth running of an institution of quality (such as facilities, didactic materials, technological media, etc.).

Planning and organization. This component, sometimes called "strategic design", is a relevant component of the general framework of an educational institution, but its supervision must take account of its dynamic. Although some authors declare that school organization has a very significant effect on the quality of educational institutions (March, 1978), some researchers consider that this organization could be a framework propitiating educational practice improvement and research on education (Scheerens, 1992, p. 118). Within the organizational profile of an educational institution, the following elements should be considered.

Mission. The feeling of mission in an institution is the expression of the aim or basic reason for its existence (Baker, 1990). This mission will determine the basic path to be followed, and will comprise the conceptual elements that define the educational project. These conceptual elements will also determine the most suitable organizational principles for the attainment of the highest levels of quality for the education provided (in its 
conception, processes, and results).

Operational principles. Operational principles will be determined by the mission that the institutions aim to accomplish. Among the possible operational principles to be adopted by educational institutions are equity, priority of attention to students, institutional autonomy, openness to communication, horizontal functional structure, atmosphere nurturing positive interpersonal relations, empowerment to the involved members, care of the environment, multidirectional intercommunication, participation of all, responsibility, continuous improvement and innovation, zero defects, immediate intervention, family involvement, institutional self-evaluation, innovative research, and educative integration and inclusion.

Organization structure. Organization structure refers to the setting up of different elements for the coordination and management of the institution, including the organs (personal or collegiate) responsible for the promotion and supervision of processes carried out within the institution. This may also include those organs or entities that, although not directly forming part of the institution's organization chart, have a relationship with it.

Written planning documents. Every institution aspiring to high levels of quality requires a number of written documents defining the strategic plan of the institution, such as the educational project, school regulations, curriculum project, year and subject programs, and annual institution memory.

Adaptation to context. Every educational institution, particularly a formalized one, is part of an educational system and is affected by this system's regulation framework. Furthermore, every institution functions within a context and an environment that affect it. In addition, students have their own personal needs, expectancies, and physical and psycho-pedagogical features that define a particular learning style and behaviour. The specific context of teachers and personnel working in the educational institution should also be taken into account.

Management of resources. This predictor of quality refers to the use of material and personal resources, and considers the following elements:

1. Management of material resources, which refers to the incidence of use of material resources in the institution and how this may affect its quality;

2. Optimization of human resources, which is particularly important, as frequent mistakes can occur if projects for quality improvement are implemented without providing guidance and suitable training for the staff and personnel, without ensuring that responsibilities are clearly defined, or without entrusting qualified people with the responsibilities they are fully equipped to undertake;

3. Strategic organizational features, which define the operational framework and the management thereof, both designed to achieve the highest level of educational quality within the institution. With reference to this aspect, Brooker, Ready, Flood, Schweitser, and Wisenbaker (1979) demonstrated that 85\% of a school's performance variance is determined by the model of social system prevailing within the school.

Educational leadership. This component plays a fundamental role as a predictor of quality. But the implementation of leadership should be considered for different fields of intervention and at different levels.

Although there are a number of descriptions of the profile of a leader, among them those proposed by Álvarez Arregui and Pérez Pérez (2011), Bolman and Deal (2008), Branson (2010), Fullan (2004; 2011) and Ogawa and Bossert (2000), we consider that:

A leader is a person (or group of persons) with the ability to provoke the liberation, from inside, of the internal energy existing in other human beings, so that these voluntarily make the effort to attain, in the most effective and comfortable possible way, the aims they themselves have decided to achieve in order to obtain their own dignity and that of those they live within the specific environment and context they are responsible for. (Gento, 2002, p. 183) 
The power to arouse creativity in other people means that a leader is also at the service of those who are being led, with the fundamental mission of helping them to overcome obstacles in order to be able to activate their full capacity to achieve their own objectives and the objectives shared with their own group. As a consequence, the art of leadership consists of "liberating people to do what is required of them in the most effective and humane possible way" (De Pree, 1989, p. XX).

\section{Dimensions of Educational Leadership}

The exercise of leadership in education can be considered on a number of different levels. The way it is implemented will vary from the role of the Minister of Education within a country, to that of a teacher in charge of a group of students and, even, to that of a student acting as a leader of his/her classmates. But, as we are referring here to leadership as a predictor of quality in educational institutions, we will consider leadership within this context.

Within an educational institution, leadership must be eminently pedagogical or educational. As a consequence, although peculiarities commonly applied to any type of leadership could be assigned to leadership within an educational institution, the main concern of the this type of leadership should be to foster the potential of all the members of the institution with the aim of achieving an education of quality, preferably within the paradigm of total quality. Figure 2 shows the different dimensions of pedagogical or educational leadership that should be identified within an educational institution.

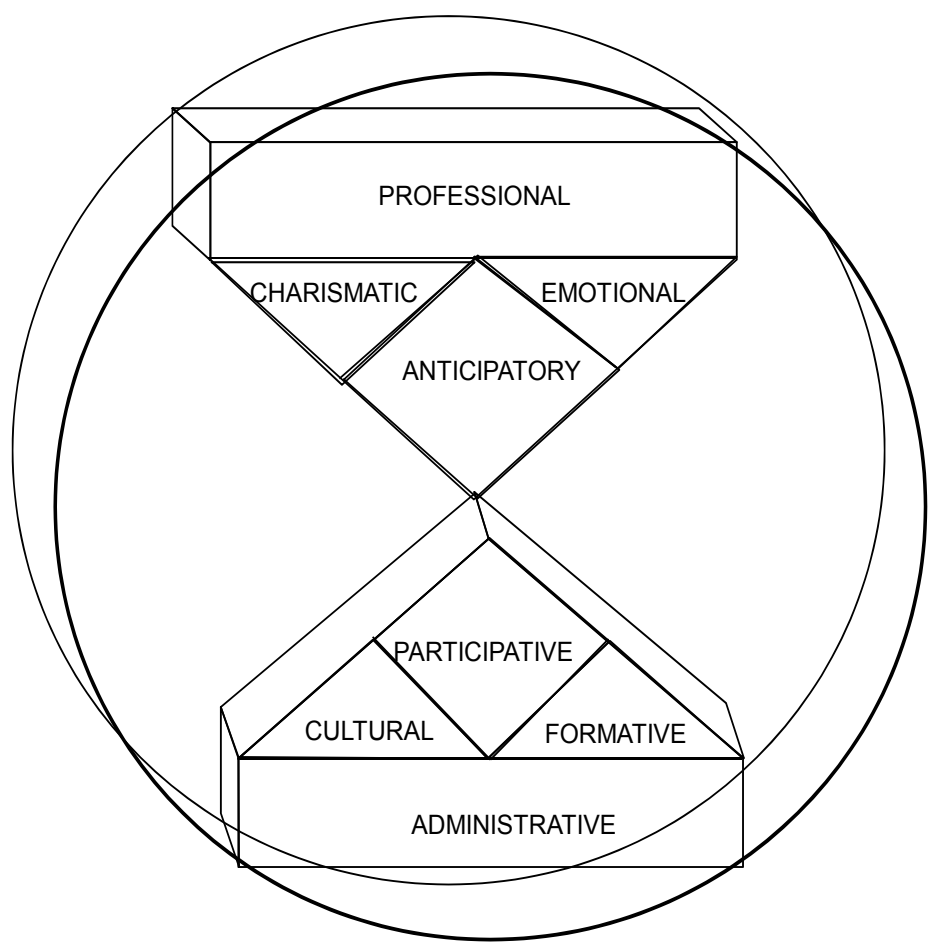

Figure 2. Dimensions of the pedagogical or educational leadership (Gento, 2002).

\section{Charismatic Dimension}

This dimension implies that the leader (whether an individual or team) is attractive enough on a personal level to enable other people to feel comfortable, and is approachable enough to inspire other people to feel confident about having a close professional relationship. 


\section{Emotional Dimension}

A leader should treat everybody in the educational institution or related to it with the greatest kindness, consideration, and acknowledgement, and at the same time, be mindful of each person's dignity and show esteem and appreciation to all people.

\section{Anticipatory Dimension}

This refers to the ability to predict the most suitable strategies and activities to solve future challenges or problems. It will also mean foreseeing the possible consequences or effects that may result from the solutions or decisions to be implemented.

\section{Participatory Dimension}

The best way of encouraging individuals and groups to engage in intelligent and collaborative work is to motivate them to offer their cooperative effort in projects they are committed to, and to participate in the decision-making process throughout every phase. Collected empirical data generally show that in schools of quality, all members of the institution work together and that its quality is increased if the educational system acts in coordination with educational institutions.

\section{Cultural Dimension}

Leaders should promote the consolidation of the institution's particular culture or specific cultural profile. Pedagogical or educational leaders should, therefore, act with the required commitment in order to clarify, consolidate, defend, and spread the institution's cultural profile.

\section{Formative Dimension}

One of the essential features of authentic leaders requires that they should take responsibility for their own continuous training and formation, and promote continuous training of the people working with them. The basic approach of this leadership dimension must, then, be the promotion of personal professional training and encouragement to obtain the best qualifications in order to carry out the tasks necessary to improve the quality of education and of the institution.

\section{Administrative Dimension}

This dimension refers to the day-to-day administration and bureaucratic activities. In order to achieve institutions of true quality, bureaucratic activities should be kept to a minimum, or at least, take second place to educational concerns. These activities cannot be totally eliminated, but it is desirable to simplify them and to ensure that they do not overshadow the fundamental aim of achieving educational institutions of quality.

\section{Empirical Research}

The paradigm or basic focus of this research is of an eclectic or mixed type (Hammersley, 1966), using qualitative and quantitative techniques with the corresponding instruments used as phases of the same continuum (Ercikan \& Roth, 2006). When circumstances allow it, data obtained by the theoretical and empirical research could be used to improve the educational or pedagogical leadership and the quality of educational institutions, of education, and of every aspect related to any one of the mentioned aspects.

The type of methodological research is essentially descriptive or interpretative and, for the initial phases we are still in, may be considered as exploratory. As descriptive and interpretative research, it aims to "describe non-manipulative variables and detect inference of generalizations" (Best \& Kahn, 2003, p. 21). As exploratory 
research, it aims to be the origin of a theory or a hypothesis or, at least, to offer new perspectives regarding the contents researched.

The final aim of this research is to transform education in order to improve its quality through the implementation of true educational or pedagogical leadership, offering proven solutions that could lead to the improvement of specific aspects, such as the input, processes, and outcome. Due to this transformative focus, our study could be considered as action research.

The techniques and instruments used for the collection of empirical data for this study are the following:

(a) Questionnaire on evaluation of the quality of educational institutions;

(b) Questionnaire on evaluation of the educational or pedagogical leadership;

(c) Semi-structured interviews;

(d) Case studies;

(e) Discussion groups.

The questionnaire on evaluation of the quality of educational institutions is designed to collect the corresponding values (from mark 1 to 9) attributed to the importance and the detected evidence (existence, reality, or effectiveness) of components and descriptors of such quality (Gento, 2001a; 2002). The nine basic components are the following:

(a) Value as an educational product;

(b) Student satisfaction;

(c) Staff satisfaction;

(d) Impact of educational product;

(e) Institution organization and planning;

(f) Management of resources (material, personal, and functional);

(g) Educational methodology;

(h) Leadership of the head or principal;

(i) Leadership of other management team members of the institution;

(j) Leadership of teachers.

The questionnaire on educational leadership aims to collect the values given (also from mark 1 to 9) regarding the importance and evidence of the following dimensions (Gento, 2001b; 2002): (a) charismatic; (b) emotional; (c) anticipatory; (d) professional; (e) participative; (f) cultural; and (g) administrative.

Semi-structured interviews have also been planned with the aim of collecting qualitative data referring to educational leadership and its repercussions on the quality of educational institutions. These interviews are to be carried out with those who have used or been evaluated by the above-mentioned questionnaires (in particular by the questionnaire on leadership) and will take into account data collected by the questionnaire on leadership and by the one on evaluation of the quality of educational institutions. The interviews will particularly show the strengths and weaknesses of leadership, the effect on education or educational institutions, and possible relevant situations of the exercise of educational leadership.

As a technique of qualitative research, the implementation of particular case studies is also planned. The use of this technique will facilitate the collection of information on the reality of educational leadership and its relevance to the quality of education and educational institutions. In some cases, they may show situations or cases where leadership is exercised with positive effects for the quality of education or the educational institution. In other cases, they may manifest specific situations where performance has a negative or pernicious 
effect. In either case, the information obtained could provide useful data to improve leadership and the quality of education.

The qualitative collection of data also includes the use of discussion groups. People participating in these groups may be professionals assuming a specific leadership role in different educational institutions or in other educational initiatives; but they might also be teachers, students, parents, teacher trainers, supervisors, or other people affected or concerned about the quality of education or educational institutions (such as administrators, politicians, etc.).

The information collected by these two last qualitative techniques (case studies and discussion groups) is not offered here, because the sample is still quite small.

\section{Results and Discussion}

Data collection began during the academic year 2011-2012. As the research is still in process and the sample is not very large, the information obtained should be considered as provisional and the result of an initial exploration of the contents. We have just now processed data obtained from the two questionnaires mentioned above, and from the semi-structured interviews. Although we insist that data are in no way definitive, we refer to the following contents:

(a) Results of the questionnaire on evaluation of educational institutions;

(b) Results of the questionnaire on leadership on educational institutions;

(c) Information collected from processed interviews.

\section{Results From the Questionnaire on the Quality of Educational Institutions}

Information collected from questionnaires on the quality of educational institutions corresponds to instruments received up until December 2013; data from questionnaires received after this data have not yet been processed. The sample includes 916 instruments: 753 proceed from European countries (Spain and Latvia), and the rest from Latin America. Table 1 reflects the number of questionnaires offered by each country.

Table 1

Questionnaires on Quality of Educational Institutions Received From Different Countries (Up to December 2013)

\begin{tabular}{lrc}
\hline Country & $N$ & Valid (\%) \\
\hline Spain & 580 & 63.3 \\
Latvia & 173 & 18.9 \\
Ecuador & 45 & 4.9 \\
Peru & 36 & 3.9 \\
Bolivia & 30 & 3.4 \\
Mexico & 28 & 3.1 \\
Colombia & 15 & 1.6 \\
Chile & 8 & 0.9 \\
Unspecified & 1 & - \\
Total & 916 & 100 \\
\hline
\end{tabular}

The information for the gender of people who filled in the questionnaire shows a small majority of females $(59.2 \%)$ and fewer males (40.8\%). The number of public institutions $(79.2 \%)$ is higher than those of the private sector $(20.8 \%)$. The majority of those who answered the questionnaire $(53.9 \%)$ proceeded from secondary 
education (33.3\% from lower secondary and $20.6 \%$ from higher secondary), but there were also representatives with university degree courses $(10.2 \%)$ and postgraduate degree courses $(10.1 \%)$, apart from others from primary $(9.9 \%)$ and even preschool education (2.5\%). Representatives of sectors who answered the questionnaire are specified in Table 2.

Table 2

Sectors Which Filled in the Questionnaire on the Quality of Educational Institutions (Up to December 2013)

\begin{tabular}{lrc}
\hline Sector & $N$ & Valid (\%) \\
\hline Students & 445 & 48.6 \\
Teachers & 246 & 26.9 \\
School principals & 64 & 7.0 \\
Parents & 89 & 9.7 \\
Inspectors/supervisors & 24 & 2.6 \\
Teacher trainers & 14 & 1.6 \\
Other & 33 & 3.6 \\
Unspecified & 1 & - \\
Total & 916 & 100.0 \\
\hline
\end{tabular}

The questionnaire used to collect information has been drawn up and revised over a period of two years and we are still continuing to review it. The questionnaires used to obtain the information shown here were submitted to processes of validation. For this purpose, Cronbach's alpha $(\alpha)$ gave the index of 0.977 . This index shows that the instrument could be considered as "valid". Apart from that, the "content" validity was guaranteed by experts from 10 different countries. They considered the questionnaire to be valid for measuring the quality of educational institutions. The "construct" validity was checked with the opinion of relevant authors on research methodology. We also collected data of the "reactive validity" obtained from those who filled in the questionnaire. Ninety-four percent of them considered that the instrument did not lack any necessary content and $72.90 \%$ considered that it had no unnecessary content.

Although the data obtained cannot be considered as definitive, we include next (see Table 3) the arithmetic mean and the standard deviation of marks assigned to the importance and evidence of basic components of quality of an educational institution.

Table 3

Evaluation of the Main Components of Quality of an Educational Institution

\begin{tabular}{lllll}
\hline Main components of quality of the educational institution & \multicolumn{3}{c}{ Importance } & \multicolumn{2}{c}{ Evidence } \\
\cline { 2 - 3 } \cline { 5 - 5 } Teachers' leadership quality & $\bar{X}$ & $S D$ & $\bar{X}$ & 1.445 \\
Leadership quality in other management team members & 7.99 & 1.178 & 7.4 & 1.329 \\
Head or principal's leadership qualities & 7.6 & 1.240 & 7.3 & 1.451 \\
Educational methodology & 7.6 & 1.319 & 7.1 & 1.089 \\
Management of resources & 7.6 & 1.121 & 7.5 & 1.215 \\
Organization and planning & 7.1 & 1.828 & 7.5 & 1.562 \\
Availability of resources & 7.3 & 1.398 & 6.94 & 1.511 \\
Impact of educational product & 7.9 & 1.117 & 7.3 & 1.592 \\
Staff satisfaction & 7.7 & 1.166 & 7.3 & 1.937 \\
Values as educational product & 8.1 & 0.956 & 6.7 & 1.485 \\
Student satisfaction & 6.7 & 1.826 & 6.6 & 1.390 \\
\hline
\end{tabular}


Considering that the range of possible marks is from 1 (minimum) to 9 (maximum), the assigned marks given to the importance of the basic components is extremely high. As might be expected, the marks assigned to the evidence are lower in general (except - surprisingly - for the "management of resources"). It is expected that as soon as the sample is increased, the differences between the importance and the evidence will be wider, most probably higher in the first category.

\section{Results of the Questionnaire on Educational Leadership}

Data on the evaluation of educational leadership proceed from questionnaires also received up until December 2013. Those received after that date have not yet been processed; they will be included in subsequent reports. The sample includes 1,027 questionnaires: 842 correspond to European countries (in particular Spain and Latvia), and the rest to Latin American countries. Table 4 includes the number of questionnaires received from every country.

Table 4

Questionnaires on Educational or Pedagogical Leadership Received From Different Countries (Till December 2013)

\begin{tabular}{lrc}
\hline Country & $N$ & Valid (\%) \\
\hline Spain & 520 & 50.6 \\
Latvia & 322 & 31.4 \\
Mexico & 74 & 7.2 \\
Peru & 42 & 4.1 \\
Ecuador & 24 & 2.3 \\
Colombia & 15 & 1.5 \\
Chile & 9 & 0.9 \\
Bolivia & 6 & 0.6 \\
Argentina & 3 & 0.3 \\
Unspecified & 12 & - \\
Total & 1,027 & 100 \\
\hline
\end{tabular}

Table 5

Sectors Which Filled in the Questionnaire on Educational Leadership (Till December 2013)

\begin{tabular}{lrc}
\hline Sector & $N$ & Valid (\%) \\
\hline Students & 468 & 46.43 \\
Teachers & 324 & 32.15 \\
School principals & 78 & 7.74 \\
Parents & 64 & 6.35 \\
Teacher trainers & 28 & 2.77 \\
Inspectors/supervisors & 11 & 1.09 \\
Other & 35 & 3.47 \\
Unspecified & 19 & - \\
Total & 1,027 & 100.00 \\
\hline
\end{tabular}

The information regarding the gender of the participants who filled in the questionnaire shows that, also here, the majority were females $(63.3 \%)$, considerably more than males $(36.7 \%)$. One-hundred and one respondents did not fill in these data. The respondents were mostly from public institutions $(81.5 \%)$, but there were also representatives from aided private institutions (12.4\%) and from totally private ones (6.1\%). Most of 
those who answered this questionnaire (52.24\%) also proceeded from institutions of secondary education (28.46\% from higher secondary and $28.46 \%$ from lower secondary), although there were also representatives from primary education $(10.85 \%)$, from university degree courses $(10.25 \%)$, from university postgraduate courses $(9.55 \%)$, from vocational education $(8.46 \%)$, and also from preschool education $(1.89 \%)$; other representatives $(7.76 \%)$ proceeded from other institutions. Twenty-two respondents of the questionnaires did not identify themselves as members of any particular institution. Table 5 next includes representatives of the different sectors who filled in the questionnaire on educational leadership.

As with the questionnaire on educational institutions, this one on educational leadership was also submitted for assessment of internal consistency to check its validity. For this purpose, the Cronbach's alpha $(\alpha)$ (that shows the average internal correlation among the items of the questionnaire) was also calculated. The obtained index was 0.997 . As a consequence, this instrument is to be considered as highly valid (as a minimum index of 0.60 indicates that an instrument may be considered as valid). The "content" validity was checked by experts from 14 countries (Argentina, Bolivia, Chile, Colombia, the Czech Republic, Germany, Israel, Japan, Latvia, Mexico, Peru, Scotland, Spain, and the United States). For the "construct" validity, the opinion of relevant authors on research methodology was considered. To check the "reactive" validity, the opinion of those who answered the questionnaire was collected. The majority of the participants (93.7\%) who answered the questionnaire expressed the opinion that the instrument did not lack any important content regarding educational or pedagogical leadership, and $82.7 \%$ considered that there was no unnecessary content on this topic.

Data processed up to December 2013 and corresponding to 1,207 questionnaires cannot be considered as definitive due to the small size of the sample. Nevertheless, Table 6 shows the values given to the importance and evidence of quality of educational or pedagogical leadership. The data included here refer to leadership in general in educational institutions; it does not differentiate among the three types of leadership mentioned by the questionnaire (school principal, other members of the school board or leadership team, and teachers). Table 6 shows the arithmetic mean and standard deviation corresponding to the mark given to each one of the dimensions of educational or pedagogical leadership (The suggested minimum possible mark could be 1 and the maximum one 9).

Table 6

Evaluation of the Importance of Educational Leadership Dimensions

\begin{tabular}{llllll}
\hline \multirow{2}{*}{ Basic dimensions of educational leadership } & \multicolumn{3}{c}{ Importance } & \multicolumn{2}{c}{ Evidence } \\
\cline { 2 - 3 } \cline { 5 - 6 } Charismatic & $\bar{X}$ & $S D$ & $\bar{X}$ & $S D$ \\
Emotional & 7.6 & 1.305 & 7.0 & 1.812 \\
Anticipatory & 7.6 & 1.541 & 7.0 & 1.654 \\
Professional & 7.5 & 1.379 & 6.9 & 1.606 \\
Participative & 7.5 & 1.585 & 7.0 & 1.785 \\
Formative & 7.5 & 1.347 & 6.9 & 1.636 \\
Administrative & 7.5 & 1.479 & 6.9 & 1.815 \\
Cultural & 7.4 & 1.614 & 6.9 & 1.763 \\
\hline
\end{tabular}

Data included in Table 6 show that, although the average marks given are quite high in both categories (from 6.8 on), the importance given to the different dimensions was considered more relevant than the evidence. 
This can be considered as an expression that educational or pedagogical leadership can be improved in any dimension. When the sample will be wider, the differences between both categories will most probably be higher, in favour of importance. Although data referring to the importance of leadership show a small range (from 7.3 to 7.6), there appears to be a small difference in favour of the charismatic and emotional dimensions (both of them with 7.6). Such differences cannot be considered as significant, but they might indicate a possibly higher relative importance of these two dimensions. It is expected that data obtained from more instruments will offer a clearer profile and, perhaps, show significant differences.

\section{Results From Semi-structured Interviews}

Semi-structured interviews were carried out after the questionnaires had been filled in. As far as possible, they were conducted with the respondents of the questionnaire or with those who had been assessed by them. An interview was initially carried out with the female principal of an institution of preschool, primary, and lower secondary education in a locality in the south of Spain. Six interviews were subsequently conducted with six professionals working in educational institutions (three principals of public or aided private schools, two directors of studies, and one teacher of a secondary public school). The sample was later extended to other professionals working in educational institutions or others involved in their operation. In total, 32 interviews received up to December 2013 were processed with the program of Analysis of Qualitative Data (AQUAD), whose author is Dr. Günter Huber. By using this program, a system of categories was defined and results appropriately systematized around the different categories. A summary of opinions is shown in Table 7, which offers a description of the most commonly mentioned traits corresponding to each one of the dimensions of educational or pedagogical leadership.

Table 7

Most Commonly Mentioned Trait for Each Dimension of Educational Leadership (Information From 32 Interviews Processed Up to December 2013)

\begin{tabular}{lll}
\hline Dimension & Most commonly mentioned trait & $N$ of mentions \\
\hline Participatory & Promotion of collaborators' team work & 47 \\
Professional & Encouragement of motivation & 36 \\
Emotional & Acknowledgment and respect for every person & 35 \\
Charismatic & Relevant professional profile; & 28 \\
Formative & Coherence and professional commitment & 28 \\
Cultural & Support for collaborators' training & 21 \\
Anticipatory & Impetus to adaptation to context & 16 \\
Administrative & Impulse to the definition of the mission of the entity & 13 \\
\hline
\end{tabular}

Data offered in Table 7 corresponding to the 32 interviewed people show some interesting information that is worthy of consideration. The participatory dimension received the highest number of mentions. According to modern literature on leadership, this dimension is the most relevant for true leadership, the basic focus of which should be to promote the intervention of collaborators or other co-workers. The other traits most commonly mentioned in relation to the other dimensions can be considered to manifest the core essence of each dimension. It is also worth stressing that the administrative dimension received the lowest number of mentions. This indicates that administrative aspects of an educational institution are less related to the essence of true educational leadership. 


\section{Conclusion}

The most recent literature proceeding from accredited authors shows that the quality of education is considered today as one of the most important factors impacting on the progress of societies and on the improvement of people. Recent studies on education also stress that true educational leadership is essential to drive change leading to improvement in educational institutions.

This study aims to gather empirical data to demonstrate the importance and evidence of the main components and elements of the quality of educational institutions and of the different dimensions of true leadership in these institutions. Through interpretative and exploratory research using a qualitative and a quantitative approach, the authors of this article aim to offer information gathered in different countries. At present, due to the as yet small sample size, the data offered here are provisional, although some trends can be detected in the opinions of the main stakeholders.

The research is still unfinished. The use of wider samples will enable us, at a later date, to offer more consistent information about the two basic topics: quality of educational institutions and educational leadership. Further empirical data are also being collected in order to correlate the evidence of quality of educational institutions with the evidence of educational leadership in these institutions. Meanwhile, the theoretical and empirical data presented here offer an opportunity to reflect on the two basic structural topics: quality of educational institutions and dimensions of educational or pedagogical leadership.

\section{References}

Álvarez Arregui, E., \& Pérez Pérez, R. (2011). Liderazgo educativo en los centros educativos de Asturias (Educational leadership in schools in Asturias, Spain). Bordón, 63(3), 9-22.

Baker, J. (1990). El poder de una visión (The power of a vision). Madison, W.I.: Chart House Learning Corporations.

Best, J. W., \& Kahn, J. V. (2003). Research in education (9th ed.). Boston, M.A.: Library of Congress.

Bolman, L. G., \& Deal, T. E. (2008). Reframing organizations: Artistry, choice and leadership (4th ed.). San Francisco, C.A.: Jossey-Bass.

Branson, C. M. (2010). Leading educational change wisely. Rotterdam: Sense Publishers.

Braslavski, C. (2004). Diez factores para una educación de calidad para todos en el siglo XXI (Ten factors of an education of quality for all in 21 st century). Madrid: Fundación Santillana.

Brooker, W., Ready, C., Flood, P., Schweitser, J., \& Wisenbaker, J. (1979). School social systems and student's achievements: School can make a difference. New York, N.Y.: Praeger.

Burbules, N. C. (2004). Leading in a culture of change. San Francisco, C.A.: Jossey-Bass/Wiley.

De Pree, M. (1989). Leadership is an art. New York, N.Y.: Bantam Doubleday.

Ercikan, K., \& Roth, W. M. (2006). What good is polirizing research into qualitative and quantitative? Educational Research, 35(5), 14-23.

Fullan, M. (2004). Leading in a culture of change: Personal action guide and workbook. San-Francisco, C.A.: Jossey-Bass.

Fullan, M. (2011). Leading system level change. In H. O'Sullivan, \& J. West-Burnham (Eds.), Leading and managing schools (pp. 16-23). London: Sage.

Gento, S. (1994). Participación en la gestión educativa (Participation in educational management). Madrid: Santillana.

Gento, S. (Ed.). (2001a). La institución educativa. I Identificadores de calidad (Educational institution. I. Identifiers of quality). Buenos Aires: Docencia.

Gento, S. (2001b). La institución educativa. II Predictores de calidad (Educational institution. II. Predictors of quality). Buenos Aires: Docencia.

Gento, S. (2002). Instituciones educativas para la calidad total (Educational institutions of total quality). Madrid: La Muralla.

Gerecht, M. (2010). Schul-und unterrichtsqualität und ihre erzieherischen wirkungen (Quality of the school and teaching and their educational effect). Münster: Waxmann. 
Hammersley, M. (1966). The relationship between qualitative and quantitative research: Paradigm loyalty versus methodological eclecticism. In J. T. E. Richardson (Ed.), Handbook of qualitative research methods for psychology and social sciences (pp. 159-174). Leicester, U.K.: British Psychological Society Books.

Hodson, P., \& Thomas, H. (2003). Quality assurance in higher education: Fit for the millennium or simply 2000 compliance. Higher Education, 45(13), 375-387.

Hopkins, D., \& Lagerweig, N. (1997). La base de conocimientos de mejora de la escuela (Basis of knowledge to improve the school). In D. Reynolds et al. (Ed.), Las escuelas eficaces claves para mejorar la enseñanza (Effective schools. Keys to improve teaching) (pp. 71-101). Madrid: Santillana.

Lomas, L. (2007). Zen, motorcycle maintenance and quality in higher education. Quality Assurance in Education, 15(4), $402-412$.

March, J. (1978). American public school administration: A short analysis. School Review, 86, 217-250.

Marín, R. (1993). Los valores, un desafio permanente (Values, a permanente challenge). Madrid: Cincel.

Ministry of Education and Science. (1994). Centros educativos y calidad de enseñanza (Educational institutions and quality of teaching). Madrid: Secretaría de Estado de Educación.

Müller-Using, S. (2010). Ethos und Schulqualität (Ethics and quality of schools). Opladen, M.I.: Budrich Uni-Press.

Murgatroid, S., \& Morgan, G. (2002). La gestión de la calidad total en el centro docente (Total quality management in an educational institution). Madrid: Centro de Estudios Ramón Areces.

Ogawa, R.T., \& Bossert, T. (2000). Leadership as an organizational quality. In Jossey-Bass (Ed.), Educational leadership (pp. 38-55). San Francisco, C.A.: Jossey-Bass.

Orden, A. (1989). Calidad de la educación (Quallity of education). Bordón, 40(2), 149-162.

Organization for Economic Cooperation and Development (OECD). (2012). Panorama de la Educación 2011: Indicadores de $O C D E$ (Panorama of education 2011: Indicators of OECD). Madrid: Santillana.

Pérez, R., \& Martínez, L. (1989). Diagnóstico, evaluación y toma de decisiones (Diagnostic, evaluation and decision making). Madrid: Rialp.

Pont, B., Nusche, D., \& Moorman, H. (Eds.) (2008). Mejorar el liderazgo escolar-Volumen 1: Política y práctica (Improving school leadership -Volume 1: Policy and practice). Paris: OECD.

Scheerens, J. (1992). Effective schooling. London: Cassell.

Scheerens, J., \& Creemers, B. P. (1989). Conceptualising school effectiveness. International Journal of Educational Research, 13(87), 691-706.

Sergiovanni, T. J. (2004). What's in it for schools? Abingdon, Oxon: Routledge Falmer.

Smith, B. L., \& MacGregor, J. (2009). Learning communities and quest for quality. Quality Assurance in Education, 17(2), 118-139.

Stoll, L., \& Fink, D. (1996). Change in schools linking school effectiveness and school improvement. Buckingham: Open University.

United Nations Educational, Scientific, and Cultural Organization (UNESCO). (1972). L'éducation dans le monde: Politique, legislation et administration de l'éducation (Education in the world: politics, legislation and administration of education). Paris: UNESCO.

Wrigley, T. (2006). Another school is possible. London: Bookmarks. 